\title{
Expresiones zoonímicas en el habla popular chilena
}

\author{
Saide Cortés* \\ Pontificia Universidad Católica de Chile
}

\section{INTRODUCCIÓN}

¿Será la oportunidad para aceptar como pertinente la vieja pregunta, "quién estuvo primero, el huevo o la gallina"?, o dirimir entre los conceptos de la Retórica tradicional que advertía dos tipos de lenguaje: uno simple, directo, desnudo y otro desviado del anterior, más complejo y adornado. ¿Quién da origen a quién? La creación de metáforas de la vida cotidiana, ¿nacerá del error o de la necesidad? La incapacidad de abstracción produciría recursos espontáneos, de poco valor, que como bien señala Kayser constituyen "una manera básica del comportamiento de la lengua" (1954: 182) y que, según manifiesta R. Castagnino, se da "no solo en literatura, sino también en el habla familiar" (1971: 204). Entonces, podemos decir que coexisten el huevo y la gallina: ambos enriquecen el lenguaje, alimentándolo de nuevas connotaciones semánticas, en evolución permanente, y dotándolo de una carga expresiva importante. Hay aquí una suerte de interdependencia entre la expresión directa y la indirecta, porque ambas son aceptadas de igual manera por el sistema de la lengua y se alimentan una a otra.

* Para correspondencia dirigirse a: Saide Cortés (saidecj@uc.cl), Departamento de Ciencias del Lenguaje, Facultad de Letras, Pontificia Universidad Católica de Chile, Campus San Joaquín, Av. Vicuña Mackena 4860, San Joaquín, Santiago, Chile. 
El habla coloquial o popular ha sido objeto de múltiples estudios cuya finalidad generalmente suele ser la creación de glosarios de términos que permitan ordenar y comprender el significado de las expresiones propias del habla de un pueblo (Huneeus 2004). Resulta importante, por lo tanto, intentar un acercamiento lingüístico más estricto y profundo para analizar este fenómeno tan común y tan relevante en la comunicación cotidiana.

En el habla chilena, tanto en su expresión coloquial como también en sus modos más formales, es posible advertir la creación y el uso masivo de expresiones que se construyen mediante nombres de animales y temas afines, que dotan a los hablantes de una amplia gama de expresividad en sus interacciones comunicativas. Este tipo de expresiones se encuentra presente en el habla de todos los grupos etáreos, sociales y geográficos, y puede observarse no solo en la expresión oral sino que tiene también manifestaciones en la expresión escrita, particularmente en diversos medios de comunicación. La publicidad, por su parte, se ha encargado de recogerlas y difundirlas. Las llamaremos expresiones zoonímicas, atendiendo a la fuerte relación que tienen con el mundo animal para expresar o hacer referencia a personas o situaciones siempre con un claro propósito humorístico.

\section{MARCO CONCEPTUAL}

En términos generales, el concepto zoonimia se utiliza para hacer referencia a los nombres y criterios de clasificación utilizados para designar a miembros del mundo animal. De esta manera, el estudio de la zoonimia, tal como se da dentro de la lexicografía, supone la consideración de la manera en que diversas comunidades lingüísticas denominan a los animales de su entorno y los clasifican según diversos criterios (Borràs 2004).

Sin embargo, al referirnos aquí al fenómeno de las zoonimias queremos designar una manifestación del nivel léxico de la lengua diferente, aunque vinculado a la designación del mundo animal. Al hablar de zoonimias aquí, queremos hacernos cargo de expresiones comunes y corrientes del habla coloquial, como: el cara de gallo, más flojo que gato de chalet o me saltó la liebre. El fenómeno que se manifiesta en estas expresiones puede ser llamado "zoonimia" y puede ser definido, en primera instancia, como una expresión neológica que utiliza la referencia a nombres de animales, sus clases, tipos, miembros, voces, etc., para designar a personas o acciones, con un evidente sentido humorístico. Esta definición de zoonimia, tal y como la 
entenderemos aquí, puede ser especificada si hacemos uso del concepto de expresión idiomática para definir el fenómeno que trataremos.

Una primera especificación de este fenómeno léxico se vincula al establecimiento de su clase dentro del sistema de la lengua. De esta manera, debemos determinar en primer lugar si el fenómeno que tratamos puede ser considerado dentro de los productos de creación léxica conocidos como neologismos o si su materia corresponde a un nivel diferente de realidad léxica. Considerando la definición que hace el diccionario de la Real Academia Española del término "neologismo", este puede ser entendido como un 'vocablo, acepción o giro nuevo en una lengua', es decir, como una creación que aumenta el caudal léxico de un determinado idioma. Los neologismos son siempre piezas léxicas únicas, aisladas, es decir, palabras sueltas que se crean y que se hacen parte de la lengua. Si bien muchas de las expresiones zoonímicas que analizamos corresponden a una sola palabra (por ejemplo: chorear, chuncho, hocicón), existen también muchas expresiones que caben dentro de este fenómeno que corresponden a estructuras mucho más complejas que una sola palabra, a pesar de que su significado sigue siendo unitario, producto del conjunto de la expresión como totalidad de sentido.

De esta manera, palabras y expresiones como: choreza, polillas, picaflor, sacar los choros del canasto, agarrar pa'l chuleteo, andar con la pluma parada, pueden ser consideradas dentro del mismo fenómeno de expresión zoonímica, pero deben ser diferenciadas en relación con su nivel de complejidad estructural, ya que las primeras corresponden a piezas léxicas simples, mientras que las segundas pueden ser muy bien consideradas dentro del campo de las expresiones idiomáticas.

Una expresión idiomática puede ser definida en términos muy sencillos como "una frase que debe ser tomada en su totalidad, y que usualmente significa algo que no se extrae del significado individual de las palabras componentes" (Rivano 2004). Esta definición básica no permite distinguir entre este fenómeno y otras construcciones léxicas, como por ejemplo las lexías complejas, que pueden ser definidas de la misma manera. Debido a lo anterior, resulta necesario ahondar, a partir de esta visión preliminar, en lo que se entiende por expresión idiomática.

En primer lugar, se debe llamar la atención sobre los múltiples criterios que se han utilizado para determinar qué es una expresión idiomática. Estos criterios van desde una perspectiva puramente semántica a una formal o funcional. Una definición de este fenómeno lingüístico que considere su complejidad y su forma de estructuración, tanto en términos de su significado como de su realidad sintagmática y las funciones que puede cumplir, puede ser realizada tomando como criterios básicos la vieja distinción saussureana 
entre sintagma y paradigma. De esta manera, podemos decir que las expresiones idiomáticas pueden ser caracterizadas por una serie de rasgos que se establecen en el nivel de las relaciones sintagmáticas o en el nivel de las relaciones paradigmáticas que en ellas se manifiestan.

Respecto de la descripción de las expresiones idiomáticas en el plano sintagmático, podemos decir que estas se caracterizan por ser una combinación de por lo menos dos palabras que se encadenan de manera única, generando un bloqueo sintáctico, es decir, conformando una unidad sintáctica indivisible e inmutable. El significado de los elementos que la componen no depende del significado que el complejo integral manifieste, sino que ambos son independientes e incluso pueden no relacionarse dentro de un mismo campo semántico. Uno de los componentes del complejo debe presentar un significado transformado, que se acerca a una expresión metafórica que sustenta el sentido total de la expresión idiomática. Estos elementos permiten caracterizar e identificar, en el plano de las relaciones sintagmáticas, una expresión idiomática.

Por otro lado, dentro del plano de las relaciones paradigmáticas, las expresiones idiomáticas pueden ser caracterizadas en relación con su estabilidad de forma y sentido, que permite que sea reproducida con libertad en diversos contextos comunicativos. Además, en este mismo plano, la expresión idiomática se caracteriza por presentar un significado integral y una integridad nominativa que no puede ser descompuesta en sus partes (Cermák 1998).

En términos mucho más específicos, podemos decir que las expresiones idiomáticas se caracterizan por cumplir con dos requisitos fundamentales que las convierten en una unidad: la fijación y la idiomaticidad. La fijación es la propiedad de estas expresiones de no ser combinaciones libres dentro de la lengua, sino de responder a moldes prefabricados de expresión, mientras que la idiomaticidad dice relación con la capacidad de estas unidades de significar en bloque y no por la suma del significado de cada una de sus partes. Respecto de ambos requisitos, si bien son esbozados ya en la caracterización sintagmática y paradigmática, se debe enfatizar su carácter necesario para la determinación efectiva de una expresión idiomática como las que aquí analizamos.

La descripción hasta aquí realizada, basada en criterios puramente lingüístico-textuales, puede ser complementada con una perspectiva más cercana a lo pragmático-discursivo, que permita incluir otros elementos característicos de las expresiones idiomáticas. Para esto, consideraremos principalmente el reciente estudio realizado por Emilio Rivano.

Un primer elemento distintivo de la expresión idiomática dice relación con su origen o base semántica. En palabras de Rivano, "las expresiones 
idiomáticas significan casos concretos, que sirven como modelos para el reconocimiento, enjuiciamiento, evaluación, caracterización de impresiones, situaciones, personas en nuestro diario vivir" (2004: 10). Esto quiere decir que el primer paso del proceso de generación de expresiones idiomáticas es la observación del mundo concreto que rodea al hablante. La observación permite detectar semejanzas entre diversos niveles de realidad y, a partir de eso, intentar explicar o referir uno mediante el otro. Esto explicaría, por ejemplo, la creación de expresiones como peleó como gato de espaldas o está más rayado que puerta de perrera, en donde se observa claramente la vinculación entre una manifestación del mundo real que se utiliza como modelo para caracterizar dos estados de ánimo o mentales de las personas.

Otro elemento que permite distinguir y señalar una expresión idiomática es lo que podemos definir como su "carácter micro-narrativo". Tal como lo manifiesta Rivano Fischer, las expresiones idiomáticas pueden ser consideradas como "narrativas con personajes, circunstancias, sicologías, descripción de situaciones, puestas en escena, asociación de imágenes, detalle de objetos $\mathrm{y}$ actitudes, conocimiento y experiencia del mundo. Todo un relato, muchas veces cristalizado en obras maestras de precisión y síntesis" (2004: 11). El autor destaca de esta manera la complejidad semántica que se encuentra en las expresiones idiomáticas, a partir de la cual se produce el sentido total de la expresión. Por ejemplo, sacar los choros del canasto remite, en palabras del autor, a una escena en la cual el mariscador o chorero es víctima del hurto de choros de su canasto mientras se encuentra recolectando más en los roqueríos, lo que le produce obviamente un sentimiento de furia y frustración. Por este intrínseco carácter narrativo de la expresión idiomática se ve explicado su significado como estructura compleja.

Un tercer elemento característico de las expresiones idiomáticas se relaciona con el nivel pragmático, particularmente con el tipo de conocimiento social o popular que puede ser expresado mediante ellas. En un nivel de funcionalidad comunicativa, las expresiones idiomáticas pueden ser caracterizadas como "un arsenal de sabiduría empaquetada, piezas filosóficas listas para aplicarlas sin el esfuerzo que demanda su imaginación y construcción lingüística previas" (Rivano 2004: 13). En otras palabras, este tipo de estructuras léxicas corresponden muchas veces a expresiones en las que se manifiesta la sabiduría popular, lo que señala el carácter coloquial, informal de este tipo de expresiones.

Habiendo definido ya el concepto de expresión idiomática con sus características principales, hemos caracterizado también el objeto de estudio de este análisis. De esta manera, cuando aquí hablemos de zoonimias, nos estaremos refiriendo a expresiones idiomáticas cuyo campo semántico y cuya 
estructura sintagmática se relaciona estrechamente con nombres de animales o, en su defecto, con referencias a sus partes o elementos característicos.

Este tipo de expresiones zoonímicas manifiesta una vinculación muy patente con la metáfora. Según Lakoff y Johnson (1980), la relación lenguajemetáfora resulta ser mucho más común de lo que parece, ya que "impregna la vida cotidiana, no solamente el lenguaje, sino también el pensamiento y la acción" (1980: 39). A primera vista se puede observar el carácter metafórico de expresiones como la cueva del lobo o la ley del gallinero, en donde se aplica una expresión a un objeto o concepto al que no denota literalmente, construyendo de esta manera una comparación que permite comprender de mejor manera el concepto o realidad en cuestión. Para estos autores, existe un continuum metafórico dentro del lenguaje, en donde es posible encontrar, en un extremo, aquellas metáforas originales, creativas, infrecuentes, que llaman la atención de quien se enfrenta a ellas y que se manifiestan más regularmente en el lenguaje de la creación poética; en el centro, aquellas metáforas más comunes y predecibles, casi lugares comunes de la expresión; y en el otro extremo, metáforas fósiles o "catacresis", expresiones tan inmovilizadas que han perdido incluso su apariencia de metáfora y parecieran ser expresiones denotativas puras. Podríamos suponer que las expresiones zoonímicas realizan un viaje desde un extremo a otro, surgiendo como metáforas creativas hasta convertirse, gracias al uso que los hablantes hacen de ellas, en expresiones tan comunes que se naturalizan completamente dentro del sistema. De ahí que, por ejemplo, el vocativo gallo o galla pudiera parecer a primera vista una forma normal de tratamiento, sin que los hablantes sean conscientes, desde un primer momento del carácter metafórico de este vocativo.

De esta manera, en el estudio y análisis de las expresiones zoonímicas se debe considerar no solo su nivel de complejidad sintagmática sino que también el nivel de fosilización o naturalización que presentan dentro del habla chilena, lo que permitirá un acercamiento mucho más acabado y efectivo a esta realidad del lenguaje.

\section{METODOLOGÍA}

El conjunto de expresiones que constituyen el corpus de esta investigación fue recolectado de diversas fuentes. Las expresiones zoonímicas fueron recogidas de muestras de habla espontánea de sujetos correspondientes 
a diversos grupos etáreos, sociales y geográficos, así como también de la investigación y análisis de diversos medios de comunicación escritos - particularmente diarios- y fuentes criollistas. Muchas expresiones fueron aportadas por estudiantes que recopilaron desde su propia habla expresiones zoonímicas. El único criterio de selección utilizado fue que en todas estas expresiones debía aparecer un animal o algún elemento vinculado al mundo animal (sus partes, sus actividades, sus hábitat, etc).

Luego de realizada la recolección de expresiones, se observó en ellas la aparición de una serie de constantes relativas a su estructura (nivel sintagmático), a su campo semántico y a sus objetivos pragmáticos. Esta revisión de constantes permitió dividir y clasificar estas expresiones atendiendo a su complejidad sintáctica, al tipo de mundo con el que se relacionan y a la función pragmática que pueden cumplir en la interacción comunicativa (ofender, halagar, retar, etc.).

\section{RESULTADOS}

El primer criterio de clasificación que puede establecerse para las expresiones zoonímicas dice relación con su complejidad sintagmática. A partir de la recolección realizada, es posible afirmar que existen diversos modos de aparición de este tipo de expresiones. En primer lugar, es posible observar la existencia de piezas léxicas simples, como por ejemplo en Ese hombre es un zorro, no seas burro o esa niña es muy cotorra. Además de estas piezas léxicas, muchas veces las expresiones zoonímicas constituyen grupos sintácticos de diversa complejidad, con diferentes funciones dentro del plano sintagmático. De esta manera, se observa la aparición de expresiones zoonímicas en varias estructuras lingüísticas, de diversa complejidad, como por ejemplo:

TABLA 1

Ejemplos de distintos tipos de estructura

\begin{tabular}{|l|l|}
\hline Tipos de estructura lingüística & Ejemplos \\
\hline $\begin{array}{l}\text { Sintagmas nominales: [sustantivo } \\
\text { zoonímico+determinantes] }\end{array}$ & $\begin{array}{l}\text { patas de gallo, cabeza de pesca'o, } \\
\text { jurel tipo salmón } .\end{array}$ \\
\hline $\begin{array}{l}\text { Formas verbales: [forma } \\
\text { verbal+zoonimia] }\end{array}$ & $\begin{array}{l}\text { hacer la chancha, cambiar carne por } \\
\text { charqui, sacar los choros del canasto, } \\
\text { morir pollo. } .\end{array}$ \\
\hline
\end{tabular}




\begin{tabular}{|l|l|}
\hline $\begin{array}{l}\text { Complementos: } \\
\text { [complemento+sintagma nominal } \\
\text { con expresión zoonímica] }\end{array}$ & $\begin{array}{l}\text { Duele como caballo, Está aburrido } \\
\text { como ostra, La cita se realizó entre } \\
\text { gallos y medianoche, Vive en la con- } \\
\text { cha de la lora, Juan peleó como gato } \\
\text { de espaldas }\end{array}$ \\
\hline $\begin{array}{l}\text { Estructuras comparativas: } \\
{[\text { más+adjetivo o }} \\
\text { sustantivo+que+expresión zoonímica }]\end{array}$ & $\begin{array}{l}\text { Más hambriento que piojo de peluca, } \\
\text { Más rayado que puerta de perrera, } \\
\text { Más perdido que chancho en misa }\end{array}$ \\
\hline Estructuras oracionales: & $\begin{array}{l}\text { Mala cueva dijo el conejo [y se cam- } \\
\text { bió de hoyo], Estoy hablando con don } \\
\text { Pancho, no con los chanchos, Al buey } \\
\text { viejo, pasto tierno. }\end{array}$ \\
\hline
\end{tabular}

Como puede observarse, existe una amplia gama de complejidad sintáctica en las expresiones zoonímicas. Al parecer, a mayor nivel de complejidad estructural, el significado de estas expresiones se vuelve algo más obtuso, es decir, mucho más cercano a una significación metafórica más compleja. Ciertamente, en cada una de estas expresiones zoonímicas puede observarse una estrecha relación con la realidad, una comparación explícita con algún elemento de la realidad. Cuando un hablante utiliza, por ejemplo, la expresión Juan peleó como gato de espaldas, está trayendo a la mente de su interlocutor la imagen real y efectiva de un gato peleando para explicar la bravura o desesperación con la que el aludido se ha enfrentado en una pelea. De esta manera, podemos decir que este tipo de expresiones zoonímicas tiene una estrecha relación con las imágenes que los hablantes pueden tener del mundo que los rodea, y particularmente, del mundo animal que pueden observar y reconocer diariamente.

La diversidad de estructuras sintácticas en las que se pueden realizar las expresiones zoonímicas implica obviamente una multiplicidad de funciones sintácticas que estas expresiones pueden cumplir. Muchos sustantivos, adjetivos y verbos se expresan con nombres de animales. En el caso de los sustantivos, muchos de estos son utilizados como vocativos de carácter coloquial, que pueden significar cercanía y confianza, pero que también pueden ser utilizados para denigrar $u$ ofender a la persona a la que hacen referencia. Respecto de los vocativos, es posible observar el uso frecuente de monomorfos supercomunes (epicenos) como dimorfos monotemáticos: 
TABLA 2

Ejemplos de vocativos

\begin{tabular}{|l|}
\hline Ese gallo es amigo mío. \\
\hline La galla que está en la esquina es súper sapa. \\
\hline Este gallo es un choro. \\
\hline
\end{tabular}

Respecto del uso de expresiones zoonímicas, llama la atención la existencia de discordancia genérica para algunas expresiones de uso común, particularmente relacionadas con la manifestación de características negativas del sujeto aludido: el gallo mula, el gallo vaca. En este tipo de expresiones, prima un criterio pragmático, de significación en la interacción comunicativa, por sobre la concordancia sintáctica necesaria. Debido a que la zoonimia gallo es adjetivada por otra expresión animal que no tiene variación de género, como mula y vaca, se produce una discordancia que no afecta la significación de la expresión. Resulta interesante que estas mismas expresiones zoonímicas (mula y vaca) pueden ser utilizadas para adjetivar diversos sustantivos, no necesariamente de carácter zoonímico, manteniéndose siempre la posibilidad de discordancia entre el sustantivo y la expresión que lo determina.

En el plano de las expresiones zoonímicas con funciones sustantivas, llama la atención la creación de piezas léxicas interesantes mediante diferentes mecanismos de formación de palabras, como creaciones por composición, por derivación o por afijación discontinua, tal como puede apreciarse en los siguientes ejemplos:

TABLA 3

Ejemplos de formación de palabras

\begin{tabular}{|l|l|}
\hline Mecanismo lexicogenético & Ejemplos \\
\hline Composición & $\begin{array}{l}\text { Este hombre no es nada, es un simple } \\
\text { pelagatos }\end{array}$ \\
\hline Derivación & $\begin{array}{l}\text { Pedro está actuando muy prepotente, está } \\
\text { todo acaballado } \\
\text { Esta comida está mosqueada }\end{array}$ \\
\hline Afijación discontinua & $\begin{array}{l}\text { Mi mamá estaba engorilada cuando le conté } \\
\text { que me eché un ramo }\end{array}$ \\
\hline
\end{tabular}

Junto con este tipo de creaciones léxicas zoonímicas, es posible encontrar otras más comunes dentro de la formación de palabras, vinculadas principalmente al uso de diminutivos y aumentativos. Mediante esta derivación de nombres de animales se crea un signo nuevo, con un nuevo significado, 
diferente a la forma léxica sin diminutivo o aumentativo. El nuevo significado depende del uso que los hablantes le den, es decir, del contexto comunicativo en el que se utilice. Esto quiere decir que el término deja de referir directamente a algún animal o a una parte de un animal para significar de manera metafórica.

TABLA 4

Ejemplos de lexicogénesis mediante diminutivos y aumentativos

\begin{tabular}{|l|l|}
\hline Diminutivos & Aumentativos \\
\hline $\begin{array}{l}\text { Como era el primero me tocó } \\
\text { ser el conejillo de indias. }\end{array}$ & $\begin{array}{l}\text { Por meterme en la pelea me llegó el } \\
\text { tremendo aletazo. }\end{array}$ \\
\hline $\begin{array}{l}\text { Este hombre es un palomilla, no } \\
\text { abandona sus malas costumbres. }\end{array}$ & $\begin{array}{l}\text { No le cuentes nada a Germán porque } \\
\text { es muy hocicón. }\end{array}$ \\
\hline
\end{tabular}

Dentro de las expresiones zoonímicas de carácter sustantivo creadas a partir de un aumentativo, llama la atención la productividad de la expresión huevón. Derivada de huevo, que consideramos parte del mundo animal por ser un producto animal y una forma de reproducción propia de la aves, la palabra huevón es característica del español de Chile, y destaca por su carácter polisémico y multifuncional. Según el contexto comunicativo en el que aparezca, huevón puede funcionar como un vocativo coloquial de carácter positivo, que señala cercanía y confianza; en otros contextos, puede funcionar como una forma de ofensa; de manera neutra, huevón puede significar simplemente hombre. Muchas veces incluso pierde su carácter significativo para transformarse en una muletilla propia del habla coloquial. Esta expresión, absolutamente lexicalizada en el español de Chile, tiene variación de género y número y deriva también en otras formas como huevada (derivada en huevá o hueá) o huevas. La primera puede tener tanto una significación neutra -es decir, reemplazar al sustantivo cosa- como una negativa. En el caso de huevas, la expresión hace referencia más bien a los testículos como una forma de señalar la posibilidad de engaño o aprovechamiento hacia alguien.

TABLA 5

Ejemplos de usos de la expresión huevón y sus derivados

Oye, huevón, te invito a un asado en mi casa el fin de semana.

¡Pucha el huevón huevón, huevón! (¡Vaya el tipo tonto, compadre!)

Me encanta esta huevá, es muy buena.

Estás haciendo puras huevadas.

No me quieras ver las huevas con este negocio. 
Otro uso muy común de las zoonimias de carácter sustantivo dice relación con la expresión toponímica, es decir, con la referencia a lugares físicos. Ejemplo de esto, Tu pieza es un chiquero, en donde se utiliza el lugar físico de los cerdos para hacer referencia al desorden y a la suciedad; o Por fin tenemos nuestro nidito de amor, en donde el nido es sinónimo del hogar. Esta misma zoonimia puede ser utilizada también con referencia a realidades de carácter más sicológico, como en la expresión Sus padres sufren del síndrome del nido vacio, o para caracterizar negativamente un lugar o una situación particular, como en Este es un nido de ratas o de víboras.

Las expresiones zoonímicas pueden ser utilizadas también como adjetivos calificativos de personas o cosas del mundo. En este uso, pueden implicar tanto aspectos positivos como negativos del referente adjetivado. Algunas características extremas de la fauna pueden ser utilizadas para expresar comportamientos análogos en las personas, como en la frase ;Qué bestia, es un salvaje!, palabras que permiten al mismo tiempo, dependiendo del contexto en el que aparezcan, construir mensajes halagadores: ¿Qué fantástico, qué salvaje: el muy bestia acertó en todo! Este ejemplo permite demostrar la productividad significativa de las expresiones zoonímicas, así como su fuerte relación con el ámbito pragmático-comunicativo de la lengua. Si bien a primera vista pareciera ser que el uso de expresiones zoonímicas como adjetivos es muy extendido, en realidad la aparición de estas se da más bien como atributos en oraciones copulativas, es decir, deben ser consideradas sintácticamente como elementos nominales, aun cuando refieran a una cualidad de un sujeto o elemento.

TABLA 6

Ejemplos de expresiones zoonímicas usadas como adjetivos/frases nominales

Esa mujer es una mosca muerta.

Tu esposo es un ratón de un solo hoyo (fiel).

Todos estos alumnos son pajaritos nuevos.

Cuidado con Juan, porque es muy picado de la araña.

En relación con las formas verbales, se observa también una gran productividad respecto de las expresiones zoonímicas. Como se dijo anteriormente, los verbos de carácter zoonímico pueden presentarse de dos maneras diferentes: como un término animal derivado como infinitivo o como una construcción de una forma verbal más una zoonimia. En el primer caso, el uso de la zoonomía como forma verbal construye una referencia relativamente directa con el significado del verbo que se crea, mientras que en el segundo caso, el significado resulta ser algo más metafórico, indirecto. 
En ambos casos, sin embargo, en innegable el matiz figurativo de la forma verbal creada a partir de la referencia a un animal. Podemos observar ambas construcciones verbales en los siguientes ejemplos:

TABLA 7

Ejemplos de construcciones verbales a partir de expresiones zoonímicas

Avispate si no quieres que te hagan tonto.

Tu hermano se achunchó cuando vio tanta gente.

Ella siempre lo engatusa con sus mimos y melindres.

Chicotea los caracoles porque vamos atrasados a la reunión.

Te fuiste al chancho con lo que le dijiste a tu amiga

Le eché la foca cuando me dijo que estaba mal.

Seguro que vas a la fiesta a puro revolver el gallinero.

Realmente le pegaste al gato con las respuestas que diste.

Los tres primeros ejemplos presentados corresponden a formas verbales que se han formado a partir de la derivación de una voz animal, es decir, se ha realizado un paso desde una clase sustantiva a una clase verbal. En el caso de Avispate si no quieres que te hagan tonto, la forma verbal proviene, obviamente, del sustantivo avispa, el cual es transformado en un verbo mediante la adición de la terminación -ar. El caso de Tu hermano se achunchó cuando vio tanta gente y Ella siempre lo engatusa con sus mimos y melindres es algo diferente, ya que la derivación que se produce desde la forma nominal a la verbal es más compleja.

En achunchar y engatusar podemos observar un proceso de afijación discontinua, en el que a los sustantivos chuncho y gato se les une un sufijo que señala su carácter verbal (la terminación - ar) y un prefijo que permite dar más coherencia a la nueva pieza verbal, generada a partir de una zoonimia. De esta manera, se observan por lo menos dos procesos mediante los cuales los hablantes crean nuevas formas verbales utilizando nombres de animales, que les permiten aumentar el caudal significativo de la lengua.

Un tercer mecanismo de creación de formas verbales mediante el uso de expresiones zoonímicas se produce a partir de la adición de una palabra del mundo animal a una forma verbal común de la lengua, suma que produce un nuevo complejo léxico, con un significado original y diferente de las partes que lo componen. Tal es el caso de Te fuiste al chancho o Chicotea los caracoles. Este tipo de complejo crea un significado metafórico que puede ser comprendido gracias a la experiencia y a la competencia comunicativa de los hablantes de la comunidad en la que estas expresiones se generan. En algunas de estas construcciones verbales, el significado del verbo principal 
se mantiene más o menos intacto (como en revolver el gallinero), mientras que en otros el significado original se pierde y adquiere otro matiz en el conjunto (como en irse al chancho).

Otro tipo de estructura sintáctica en la que se manifiestan las expresiones zoonímicas es el complemento, particularmente de tipo circunstancial. Llama la atención la gran productividad que las expresiones basadas en elementos del mundo animal tienen dentro del habla coloquial para describir acciones y situaciones de manera certera y significativa. En este tipo de estructuras sintácticas se manifiesta la enorme capacidad de observación y relación que los hablantes tienen respecto del mundo que los rodea y la lengua que utilizan, ya que muchas -por no decir todas- las expresiones zoonímicas que se construyen como complementos actúan como elementos comparativos entre la referencia del mundo animal y el elemento del discurso que el hablante compara.

La mayor parte de los complementos zoonímicos encontrados son encabezados por la preposición comparativa "como". A pesar de esto, es posible observar, aunque en menor medida, complementos circunstanciales de lugar y de tiempo dentro de las expresiones zoonímicas. La proliferación de complementos de carácter comparativo puede ser explicada por el carácter figurativo y de imagen que la alusión al mundo animal y sus elementos tiene. Algunos ejemplos de expresiones zoonímicas en estructura de complemento son los siguientes:

\section{TABLA 8}

Ejemplos de expresiones zoonímicas en estructura de complemento

\begin{tabular}{|l|}
\hline Estoy pensando en la inmortalidad del cangrejo. \\
\hline Esa música está a todo chancho \\
\hline Mi abuela se acuesta con las gallinas. \\
\hline Quedé como gato mirando para la carnicería con tan poca comida. \\
\hline Me quemé como jaiba en la playa. \\
\hline Con los calmantes que me dieron dormí como un lirón. \\
\hline
\end{tabular}

Como se observa en los ejemplos, si bien los complementos encabezados por "como" parecen ser más comunes, es posible encontrar también otro tipo de preposiciones al inicio de los complementos. Dentro de esta gama, se observan complementos de modo (Esa música está a todo chancho), de tiempo (Se acuesta con las gallinas) e incluso suplementos, como en el primer ejemplo. Llama la atención en estos casos la aparente discordancia que existe entre la preposición que encabeza el complemento y la circunstancia a la que este hace referencia. La preposición "con", por ejemplo, pareciera ser 
más apropiada para establecer una relación de compañía o de instrumento, pero en este caso está señalando, con el conjunto del complemento, una circunstancia temporal, que solo puede ser comprendida por un hablante que participe de la comunidad de habla en la que esta expresión zoonímica se ha producido.

Una estructura muy productiva para la aparición de expresiones zoonímicas es la estructura comparativa [más $+\ldots+$ que $+\ldots$. J Junto con los complementos encabezados por "como", este tipo de construcción permite relacionar y caracterizar sujetos y situaciones mediante una referencia a la realidad animal que los hablantes observan. Las comparaciones pueden ser utilizadas para expresar tanto matices positivos como negativos del elemento que determinan. En términos de significado, las comparaciones zoonímicas se construyen haciendo una referencia directa a una imagen real y efectiva observada en el mundo animal que es extrapolada e igualada a un sujeto o situación que quiere ser caracterizada. Esta caracterización se realiza con un innegable matiz humorístico que amplía la interpretación de la expresión y la sitúa en un plano eminentemente pragmático. En la construcción de estas expresiones comparativas pueden utilizarse como elementos zoonímicos tanto nombres de animales como partes o elementos relacionados de y con ellos. Algunos ejemplos:

\section{TABLA 9}

Ejemplos de estructuras comparativas construidas a partir de expresiones zoonímicas

Tu primo es más pesado que consomé de ballena.

Este auto está más arreglado que caballo de circo.

Dame un vaso de agua, estoy más seco que escupo de camello.

Jaime quedó más contento que perro con pulgas con su regalo.

Doña Rosa es más chueca que peo de culebra.

Pedro no presta nunca sus cuadernos, es más cagado que palo de gallinero.

Mi hermano es más flojo que gato de chalet.

Para que estas construcciones puedan ser consideradas expresiones zoonímicas es necesario que en ellas se manifieste un grado de inmovilización que permita reconocerlas como frases fosilizadas que son usadas tal cual como aparecen por diferentes hablantes para significar lo mismo. Debido a que la estructura comparativa es muy productiva, es posible encontrar alguna comparación que utilice un elemento animal que aún no manifieste ningún grado de inmovilización, que sea utilizada por un hablante como parte de su idiolecto o que haya surgido de manera creativa en alguna interacción 
comunicativa. Para que un enunciado de este tipo pueda ser considerado efectivamente como una expresión zoonímica es necesario que se convierta en una estructura fuertemente amalgamada y que pueda ser parte del habla de todos o de gran parte de los hablantes de una comunidad.

Otro aspecto interesante de este tipo de construcción, y en general de todas las expresiones zoonímicas de estructura compleja, dice relación con el nivel de abstracción y de metaforización que manifiestan. Debido a que se encuentran en lo que podríamos denominar metáforas intermedias (siguiendo a Lakoff y Johnson 1980), requieren que los hablantes, para comprenderlas, interactúen de manera efectiva con su comunidad de habla y sean capaces además de distinguir las relaciones que existen entre el mundo referido por la expresión zoonímica y el mundo de los sujetos comparados con ella.

El máximo nivel de complejidad sintáctica y de inmovilización o fosilización semántica en términos de las expresiones zoonímicas se manifiesta en las estructuras oracionales. En este plano encontramos todas aquellas expresiones como dichos y refranes, propios del habla popular, que se construyen a partir de la referencia a algún elemento del mundo animal. En este plano de las construcciones oracionales, el significado ya no está referido a un concepto o signo de carácter individual, sino que es más bien un complejo significativo. Los refranes o proverbios expresan una idea, consejo, advertencia, reflexión, que no puede ser expresada en una sola palabra. Estas frases pueden ser de carácter universal, como la mayoría de los refranes y proverbios, o pueden ser propios de una comunidad de habla, en este caso, del español de Chile. Algunos ejemplos:

TABLA 10

Ejemplos de estructuras oracionales construidas a partir de expresiones zoonímicas

\begin{tabular}{|l|}
\hline Trillar con burros es para que puro caguen la paja. \\
\hline Camarón que se duerme se lo lleva la corriente. \\
\hline La culpa no la tiene el chancho, sino quien le da de comer. \\
\hline Chancho limpio no engorda. \\
\hline En la noche todos los gatos son negros. \\
\hline Peor es mascar lauchas. \\
\hline Vamos arando dijo la mosca subida en el cacho del buey. \\
\hline Al ojo del amo engorda el caballo. \\
\hline Más vale pájaro en mano que cien volando. \\
\hline
\end{tabular}


La mayor complejidad de las estructuras zoonímicas, tal como ha sido presentada hasta ahora, parece implicar dos principios o características principales: primero, un mayor grado de inmovilización del significado de la estructura zoonímica mientras más compleja esta sea; segundo, una relación de significación más lejana entre lo denotado y la estructura lingüística que lo denota. De esta manera, la comprensión de este tipo de expresiones por parte de los hablantes requiere necesariamente una inserción efectiva de estos dentro de su comunidad para que sea la interacción comunicativa con los pares la que permita conocer, entender y utilizar de manera coherente este tipo de expresiones.

Junto con un criterio formal-estructural, las expresiones zoonímicas pueden ser clasificadas y agrupadas de acuerdo a núcleos temáticos relativamente definidos. Si bien resultaría imposible intentar agotar todos los temas alrededor de los cuales giran las expresiones zoonímicas, puede ser interesante hacer referencia al menos a algunos temas recurrentes o fácilmente observables dentro del corpus analizado. De esta manera, podemos hacer referencias a tres temas diferentes dentro de los cuales se pueden clasificar o incluir algunas expresiones zoonímicas: el tema social, el tema amoroso y el tema policial.

Respecto del primero, se observa la presencia de expresiones zoonímicas utilizadas para hacer referencia a las tres clases sociales principales: a las personas de clase alta, se les denomina pepe pato o jaibón; la clase media es conocida como la gente de medio pelo, mientras que a las personas de la clase más pobre se les suele llamar ratón de cola pelá o pobre ave. $\mathrm{Si}$ alguien pretende ascender en la escala social, se le acusa de piojo resucitado, de ave que se viste con otras plumas e incluso se le hace saber que aunque la mona se vista de seda, mona se queda. En lo relativo al dinero, quien lo posee anda con lana, mientras que quien no lo tiene anda a palos con el águila o está pato.

En el tema amoroso, las expresiones zoonímicas resultan ser también muy productivas. Los pretendientes suelen ser llamados moscardones, abejorros o jotes, en alusión directa al hecho de que rondan alrededor de la joven a quien pretenden. Estas tres expresiones manifiestan un tono peyorativo y humorístico respecto del joven enamorado. Cuando su interés es muy manifiesto y encuentra alguna respuesta en la amada, se dice este huevito quiere sal. Los besos se denominas patos y piquitos, según sea la intensidad de este. Los tratamientos cariñosos entre los miembros de una pareja suelen corresponder a nombres de animales: perrito/a, chachi, monito, osito, ratoncita, etc. Una mujer experta en temas amorosos se denomina zorra correteá; la virginidad femenina se manifiesta diciendo que la aludida tiene 
una tela de araña. El amante se denomina popularmente el patas negras, $\mathrm{y}$ el encuentro sexual o el lugar donde ocurre se llama pollito al velador.

Finalmente, en el tema policial o delictual también es posible encontrar el uso de diversas expresiones zoonímicas. Los delincuentes suelen denominarse patos malos; el jefe de la banda es el pez gordo, y sus delitos pueden nombrarse de diferentes maneras: chanchullo, robo hormiga, meter mula. Robar puede ser chorear, chivatear, cogotear. Los soplones dentro de un grupo delictual se denominan loros o sapos. Obtener éxito en alguna actividad delictual es dar un zarpazo. Como consejo policial, destruye al león cuando aún es cachorro, pero eso sí, avíspate porque gatos con guantes no cazan ratones.

La utilidad y productividad de las expresiones zoonímicas es innegable. Aparecen en insultos como ¡huevón, hijo de perra!, en advertencias como te conozco, mosco, me extraña, araña; como fórmulas de saludo y despedida: ¡hola, ratón con cola!, chao, pesca'o, es decir, son una forma común de utilizar el lenguaje cotidiano e informal para comunicarse entre miembros de una comunidad.

\section{CONCLUSIONES}

El estudio descriptivo de las expresiones zoonímicas pone de manifiesto su relevancia dentro de la comunicación cotidiana entre los miembros de una comunidad, así como su productividad para construir y transmitir diferentes significados que permiten comprender y verbalizar de manera más completa la realidad. Si bien a primera vista puede parecer que este tipo de expresiones es propio de un estrato social o de un tipo de habla extremadamente coloquial, las expresiones zoonímicas se encuentran de manera transversal en todos los hablantes de nuestra comunidad lingüística y en innumerables esferas discursivas y textuales.

Un elemento interesante a destacar resulta ser la variedad de complejidad estructural en la que pueden presentarse las expresiones zoonímicas y la forma en que esa complejidad se relaciona con la manera en que la expresión significa y con el nivel de fosilización que presenta. Este es un aspecto sobre el cual resultaría interesante profundizar, para establecer relaciones más claras entre inmovilización, metaforización y complejidad sintáctica.

Otro aspecto sobre el cual puede profundizarse dice relación con los temas principales alrededor de los cuales giran las expresiones zoonímicas, 
así como también la determinación de los referentes del mundo animal más comunes en las expresiones zoonímicas del español de Chile. Asimismo, otra proyección de este análisis descriptivo dice relación con la recopilación de expresiones zoonímicas características del español de otras comunidades lingüísticas de América, para relevar semejanzas y diferencias en este tipo de expresiones.

Un estudio de este tipo resulta relevante considerando el nivel de competencia comunicativa y discursiva que se requiere para comprender y utilizar este tipo de expresiones ya que, tal como se manifestó, su creación y uso están íntimamente ligados con una comunidad lingüística particular. De este modo, la comprensión del fenómeno de las zoonimias puede ser útil no solo como una descripción de un aspecto de la lengua en uso, sino también desde una perspectiva didáctica, vinculada principalmente con la enseñanza del español a extranjeros. 


\section{REFERENCIAS BIBLIOGRÁFICAS}

Borràs, LaURa. 2004. Los artículos lexicográficos de zoónimos en diccionarios españoles de lengua general. Tesis de doctorado, Universidad Pompeu Fabra.

Castagnino, Raúl. 1971. ¿Qué es Literatura? Buenos Aires: Editorial Nova.

Cermák, Frantisek. 1998. La identificación de las expresiones idiomáticas. En Juan de Dios Luque Durán y Antonio Pamies Bertrán. Léxico y fraseología. Granada: Método Ediciones, pp. 1-18.

Huneeus, Pablo. 2004. Dichos de campo: los mejores proverbios y refranes del habla castellana. Santiago: Nueva Generación.

Kayser, Wolfgang. 1954. Interpretación y análisis de la obra literaria, $4^{\mathrm{a}}$ edición. Madrid: Gredos.

Lakoff, George y Mark Johnson. 1980. Metáforas de la vida cotidiana. Madrid: Cátedra.

Rivano, Emilio. 2004. De las expresiones idiomáticas. Cognición, Imaginación, Categorización, Creatividad, Lenguaje. Con un glosario de expresiones chilenas. Concepción: Universidad de Concepción. 